\title{
Comunicação e educação: um contributo para pensar a questão ambiental
}

\author{
Adilson Citelli \\ Professor Titular no Departamento de Comunicações e Artes da ECA-USP. Ministra cursos de \\ graduação junto ao referido departamento e de Pós-Graduação no Programa de Ciências da \\ Comunicação (PPGCOM-USP). Pesquisador 1C do CNPq. É autor de inúmeros livros e artigos \\ voltados aos campos da Comunicaşão, da Linguagem e da Educomunicação. \\ E-mail: citelli@uol.com.br \\ Sandra Pereira Falcão \\ Doutoranda do Programa de Pós-Graduação em Ciências da Comunicação da ECA-USP. \\ Bolsista do Conselho Nacional de Desenvolvimento Científico e Tecnológico (CNPq). \\ E-mail: sandrapfalcao@hotmail.com
}

Resumo: Analisamos a interface comunicação-educação como elemento central na construção de sentidos ambientais proativos entre habitantes urbanos. Por meio de lastro teórico multirreferenciado e com apoio em dados de campo, buscamos compreender como a comunicação socioambiental é tratada na dinâmica da urbe. Os achados sinalizam a necessidade de gerar, potencializar e fazer circular/ interpretar, em sistema de retroalimentação, elos que facultem aos moradores de conglomerados humanos refletir e agir diante das circunstâncias que reduzam a sua qualidade de vida.

Palavras-chave: comunicação; educação; sustentabilidade; meio ambiente; educação ambiental.
Abstract: We analyse the interface between communication and education as a key element to build proactive environmental sense among urban citizens. Through multi-referenced theoretical ballast and with support on field data, we seek to understand how environmental communication is handled in the dynamics of the city. These findings suggest the need to generate, potentialize and allow circulation/ interpretation - in a feedback system (of) links to make the citizens of human conglomerates reflect and act facing the circumstances that reduce their life quality.

Keywords: communication; education; sustentability; environment; environmental education.

\section{INTRODUÇÃO}

Diante do panorama de crescente preocupação envolvendo o meio ambiente, deparamo-nos com óbices complexos referentes à apropriação da comunicação ambiental quando afeita aos sujeitos que habitam áreas geográficas profundamente alteradas pela atividade antrópica. 
1 LATOUCHE, S. Pequeno tratado do decrescimento sereno. São Paulo: Editora WMF Martins Fontes, 2009.

2 Muniz Sodré alerta para a neutralização ou pasteurização da "dinâmica tensional inerente ao jogo democrático da cidadania ativa" operada pela expansão do consumo "no quadro confortável da inserção dos indivíduos no mercado de trabalho"

- o que tem acontecido "sem conflitos, ao contrário do que costuma ocorrer no plano dos direitos reais ou daqueles ligados ao trabalho" (SODRÉ, 2014, p. 297). Trata-se de mais um viés para a análise dos aportes midiáticos vinculados à questão socioambiental.

3 SALDIVA, P. et al. Meio ambiente e saúde: o desafio das metrópoles. São Paulo: Ex-Libris Comunicação Integrada, 2010.

$4 \mathrm{O}$ distrito Vila Medeiros (subprefeitura V. Maria - V. Guilherme) possui $7,80 \mathrm{~km}^{2}$, população total de 129.919 habitantes (cf. censo 2010-IBGE), e múltiplos problemas socioambientais. Abrange os bairros: V. Medeiros, V. Sabrina, V. Ede, V. Gustavo, V. Munhoz, V. Nivi, Jd. Brasil, Jd. Julieta, Parque Rodrigues Alves, Conjunto Promorar Fernão Dias e uma parcela de bairros circunvizinhos, como o Parque Edu Chaves.

5 Os dados de campo que subsidiaram a elaboração deste artigo - a partir dos quais os autores promoveram reflexões acerca da questão ambiental e dos seus vínculos com a educomunicação - foram extraídos da pesquisa de mestrado finalizada em 2013 por Sandra P. Falcão, no PPG COM da ECA-USP, sob a orientação do Prof. Dr. Adilson Citelli.
Tais obstáculos criam e mantêm uma espécie de "jogo de esconde" protagonizado pelo poder econômico característico do capitalismo de alto consumo, no qual a criação/manutenção dos valores socioambientais passa por filtros com características mais publicitárias do que propriamente dirigidas à resolução de adversidades que matizam a realidade e a vida social. O exemplo mais óbvio é o modo como a crise de abastecimento de água na cidade de São Paulo vem sendo tratada.

Vale dizer, conserva-se a todo custo, em termos globais e locais, o modelo mercantil a ditar como se alcançará a sustentabilidade no interior de um sistema em que o paradigma é aquele vinculado à obsolescência planejada ${ }^{1}$. Nesse cenário, algumas iniciativas de recuperação ambiental contrastam com fluxos comunicativos, muitas vezes advindos da mídia, que reverberam a visão do ambiente como espaço voltado ao capital, e não como lugar de "construção-reposição-(con)vivência”. Claro está que não pretendemos aqui demonizar a totalidade da mídia, mas apenas assinalar que em meio às procedentes contribuições representadas por produções jornalísticas voltadas à questão socioambiental existem, também, enfoques de duvidoso contributo.

Assim, recebemos diariamente mensagens-amálgama, de fontes diretas ou difusas, que refletem a valorização do termo "qualidade de vida", mantendo-o, porém, atrelado ao enorme consumo de bens materiais ${ }^{2}$. Cresce, contudo, entre habitantes dos grandes centros urbanos, um desconforto representado pelas pressões múltiplas que atravessam o cotidiano, e, embora tal percepção soe óbvia, ela precisa ser destacada em um rol de reflexões intimamente conectadas à busca da qualidade de vida como condição estruturante do papel central reservado ao ser humano na reversão de prejuízos socioambientais ${ }^{3}$.

O horizonte em foco neste artigo é o de tentar entender como a questão socioambiental é tratada na dinâmica urbana. Para isso, realizamos pesquisa na região nordeste da cidade de São Paulo (distrito Vila Medeiros ${ }^{4}$ ), envolvendo 185 sujeitos de pesquisa (179 moradores e seis servidores da prefeitura diretamente relacionados às atividades do poder público no lócus de investigação). A amostra relativa aos moradores estratifica-se em três grupos: 57 adultos, 62 jovens cursistas do ensino médio e 60 jovens do ensino fundamental. Sobre ela iremos nos deter em seguida.

\section{EM TORNO DA PESOUISA}

No distrito paulistano em que se realizou a investigação ${ }^{5}$, foi constatado que a minoria dos respondentes declara-se confortável ao caminhar pelas ruas de seu bairro. Os resultados demonstram que, de 179 pessoas (o total da amostra correspondente aos moradores), 105 (ou 58,66\%) manifestam oscilação entre mal-estar e bem-estar, conforme o logradouro pelo qual passam, enquanto 38 pessoas $(21,23 \%)$ declaram sentir frustração e tristeza com a paisagem encontrada nas ruas da região onde moram. 
Também foi possível notar que essa sensação de desconforto se amplia conforme avança a faixa etária dos respondentes: para os jovens do ensino fundamental ela é menor (11,67\%), para os do ensino médio alcança $19,35 \%$, enquanto para os adultos o indicador salta para 33,33\%. Parece-nos, desta sorte, que o desgaste relacionado aos sentimentos negativos diante do espaço circundante acompanha de maneira crescente os moradores. $\mathrm{O}$ índice dos que manifestam satisfação com o meio ambiente ao se deslocarem pelo bairro é reduzido para todos os grupos, sendo que, em relação aos demais segmentos, apenas os jovens do ensino fundamental revelam bem-estar absoluto um pouco maior.

Tal maioria, a confirmar diferentes graus de mal-estar urbano - vinculados, especificamente, à temática deste artigo —, revela, entretanto, nunca ter acionado o poder público por meio dos canais de comunicação da prefeitura em busca de melhorias socioambientais para o seu distrito, bem como assevera não haver sido informada pelas autoridades acerca dos problemas que acometem o meio ambiente, ou mesmo sobre ações existentes na região para minimizá-los ou combatê-los, conforme atestam os gráficos abaixo:

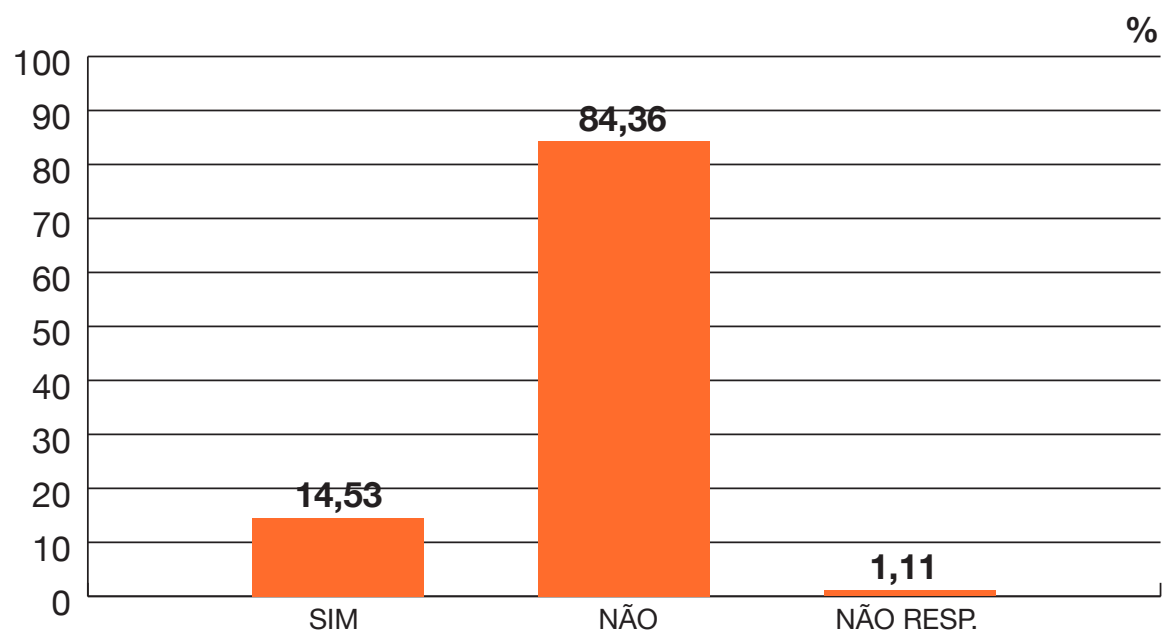

Gráfico 1 - Já se comunicou com o poder público quando percebeu algum problema ambiental no seu bairro?

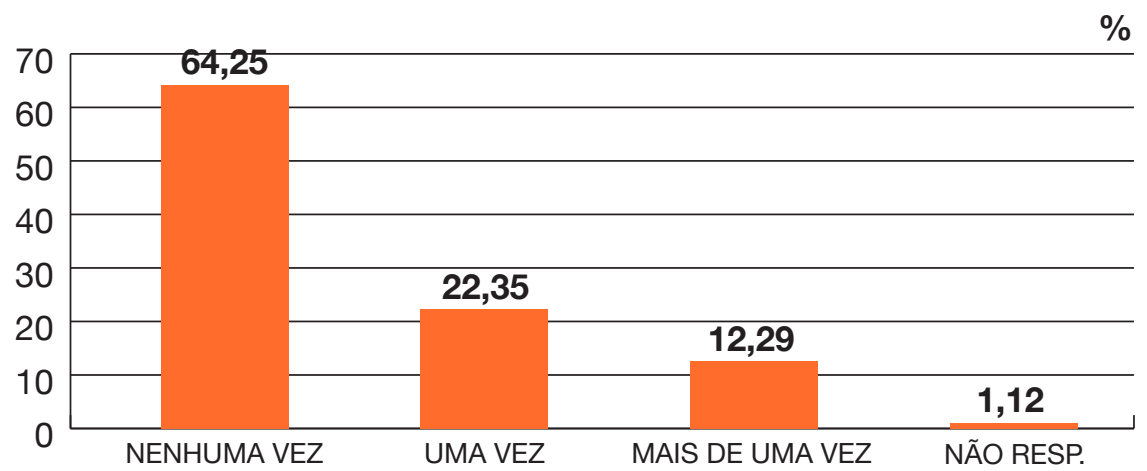

Gráfico 2 - Com que frequência recebeu informações do poder público, no último ano, sobre problemas ambientais da região ou sobre atividades promovidas para combatê-los? 
Os segmentos populacionais afeitos à nossa pesquisa (cujo rol de idades oscila entre 13 e 80 anos) demonstram conhecer as mazelas ambientais existentes e revelam algum entendimento quanto às suas causas. Falta-lhes, entretanto, disposição maior para a participação nos debates relativos à esfera ambiental urbana. Isso nos leva, como educadores, a pensar em propostas que ajudem no redirecionamento da vida associada e que sejam capazes de ir além dos atuais determinativos mercantis - para os quais as cidades viraram lugares a ser ocupados pela dinâmica da expansão imobiliária, com seus interesses especulativos, raramente consoantes com as necessidades dos cidadãos.

Pensamos que acionar as possibilidades oferecidas pela interface comunicação-educação pode contribuir para melhorar a compreensão da temática do meio ambiente, tendo em vista as potencialidades oferecidas pelo conhecimento mais detalhado dos processos que envolvem a produção, circulação e recepção das mensagens e discursos afins. Tal movimento enseja promoção educacional capaz de aproximar a cidadania (sobretudo dos jovens que frequentam o ensino básico) dos mecanismos reflexivos e deliberativos em torno dos problemas constituídos pelo rizoma comunicativo que envolve a educação socioambiental.

Por esta via, ao mobilizar o potencial contido no movimento entre a comunicação (compreendidos desde os dispositivos tecnológicos até a própria construção das mensagens) e a educação, viabiliza-se o debate sobre a questão socioambiental de forma mais orgânica e articulada. Da mesma maneira, ativar a interface comunicação/educação faculta-nos pontuar algumas contribuições daí resultantes para o debate proposto neste artigo: a) ensejar motivação para a busca de sentidos despidos do véu cintilante disposto pelo mercado à frente de qualquer reflexão mais questionadora sobre o meio ambiente; b) solicitar ações abrangentes do poder público em direção ao aprimoramento dos modelos administrativos que têm como função promover a coparticipação do cidadão em projetos para a reversão de agravos ao ambiente; c) encorajar os cidadãos comuns a enfrentar interesses econômicos de grupos que ferem o direito, individual e comunitário, a uma existência saudável; d) promover transformações em contextos escolares, que conduzam à percepção segundo a qual as salas de aula não estão desconectadas do seu entorno e por isso lhes cabe, de maneira inequívoca, contribuir para tratar dos agravos ambientais, que, em cidades como São Paulo, se tornam gritantes em bairros periféricos.

\section{COMUNICAÇÃO AMBIENTAL URBANA E QUALIDADE DE VIDA}

Ainda que em escala distante da ideal, amplificam-se entre os cidadãos as preocupações relativas aos problemas ambientais globais e locais, seja graças à constatação pura e simples de que os recursos naturais são finitos (e mais uma vez o racionamento de água em São Paulo, Rio de Janeiro ou Minas Gerais exemplifica a gravidade do problema), seja por conta do trabalho incessante 
dos veículos de comunicação para tornar esse debate e seus desdobramentos acessíveis à população. De toda forma, independentemente da unidade midiática a dar voz aos impasses, é notório que tanto as vertentes mais comprometidas da comunicação social (incluindo a mídia especializada em meio ambiente) quanto aquelas de duvidoso contributo guarnecem a audiência de argumentos loquazes para situar a temática. Em contrapartida, a despeito de haver sido ampliado o envolvimento dos cidadãos e cidadãs com o conjunto de assuntos relacionado à discussão socioambiental, em termos gerais, "a grande maioria da população jamais participou de alguma forma de organização social que vise a promoção da qualidade de vida" .

Para Giacomini Filho, esse conceito firma-se como uma composição de múltiplos fatores, de maneira que "cada atividade social ou ambiental pode estar relacionada com a qualidade de vida e sob este prisma ser estudada". Segundo o autor, a comunicação social deve ser vista como elemento basilar, pelos mais diferentes ângulos sob os quais se abordem os parâmetros vinculados ao aspecto qualitativo da vida humana, porque "o processamento da informação é fundamental nos procedimentos de tomada de decisão, seja no âmbito do consumidor, do cidadão ou da sociedade" ${ }^{7}$. Tal exercício analítico torna viável identificar, por distintos caminhos, as práticas que mais poderiam contribuir para que fosse repensado o modo de viver nas grandes cidades.

Ademais, diante da constatação de Giacomini — ainda válida, embora publicada há alguns anos — de que tanto as instituições quanto os instrumentos de comunicação social têm se empenhado mais em trabalhar aspectos ambientais vinculados às dificuldades cotidianas em urbes de grande porte, como São Paulo, intrigam-nos os resultados tímidos obtidos diante da urgência absoluta de providências concretas implantadas em larga escala. Para efeito comparativo — embora noutra latitude —, reportemo-nos à China, que não é propriamente um modelo de atenção socioambiental, mas que vem tomando providências no sentido de implantar um cinturão verde com centenas de quilômetros de extensão para combater os graves distúrbios ambientais que se abatem sobre algumas de suas principais cidades em decorrência da expansão econômica predatória das últimas décadas ${ }^{8}$. A fim de exemplificar, em território brasileiro, certas "ausências inexplicáveis", basta observarmos que um dos problemas relacionados à falta de água na cidade de São Paulo é o desmatamento nas áreas próximas ao sistema Cantareira. E isso foi feito tanto para a ampliação de pastagens (logo, o caráter agressivo de certo tipo de exploração econômica da terra) quanto para abrigar ocupações irregulares (outra face ligada ao uso do solo urbano, que lança, para além das periferias, enormes contingentes humanos). Equivale afirmar, falamos de um movimento ancorado em certas dinâmicas do capital que tratam a questão do ecossistema, na melhor das hipóteses, como mero exercício retórico.

Em busca de respostas para o que, no cenário aventado, conecta-se à perspectiva de escrutínio da linguagem do descompromisso com o meio ambiente urbano, nosso itinerário investigativo considera residir na comunicação uma das
6 LOUREIRO, C. F. B.; LAYRARGUES P. P.; CASTRO, R. S. (orgs.). Sociedade e meio ambiente: a educação ambiental em debate. São Paulo: Cortez, 2008, p. 31.

7 GIACOMINI FILHO, G. Comunicação e qualidade de Vida. In: DENCKER, A. F. M.; KUNSCH, M. M. K. (orgs.). Comunicação e meio ambiente. São Paulo/São Bernardo do Campo: Intercom/Imes, 1996, pp. 41-42.

8 Ver: Com mais de 50 bilhões de árvores plantadas, China tem o maior programa de reflorestamento do mundo. Disponivel em: <http:// operamundi.uol.com.br/ conteudo/noticias/34676/ revista+samuel+a+grand e+muralha+verde.shtml>. Acesso em: 19 mar. 2015. 
instâncias decisivas (conquanto nem sempre dirigida aos reais interesses da cidadania) para promover informação qualificada acerca da questão socioambiental.

É imperioso observar, ainda, que ao falarmos dos processos comunicacionais damos a eles dimensão maior, que não diz respeito apenas à grande mídia, mas também se refere a circuitos localizados que possam melhorar os fluxos de informação entre os setores públicos e os moradores de um bairro ou uma região da cidade - por exemplo, no que se refere a possíveis estratégias de comunicação pública levadas a termo por uma subprefeitura. Desse descompasso referente à comunicação ambiental resulta que os discursos envolvendo os temas da água, das árvores, das formas de ocupação espacial passam ao largo do cidadão e conduzem para dois tipos de silêncio da voz do "contribuinte": de um lado há o viés, por exemplo, da publicidade imobiliária, que afirma de modo unidirecional os princípios do inexorável crescimento urbano, e das possíveis compensações ambientais pela derrubada de quarteirões inteiros nas grandes cidades, e, de outro, a impossibilidade de o morador encontrar circuitos de comunicação que promovam o diálogo entre ele e o poder público.

Nossos sujeitos de pesquisa comprovaram essa constatação em diversos momentos do percurso. Quando indagados acerca de possíveis alterações fomentadas pela comunicação ambiental em circulação no distrito em que se circunscreve nosso trabalho, a maioria afirmou que ela não tem interferido no comportamento dos moradores, conforme explicita o gráfico abaixo:

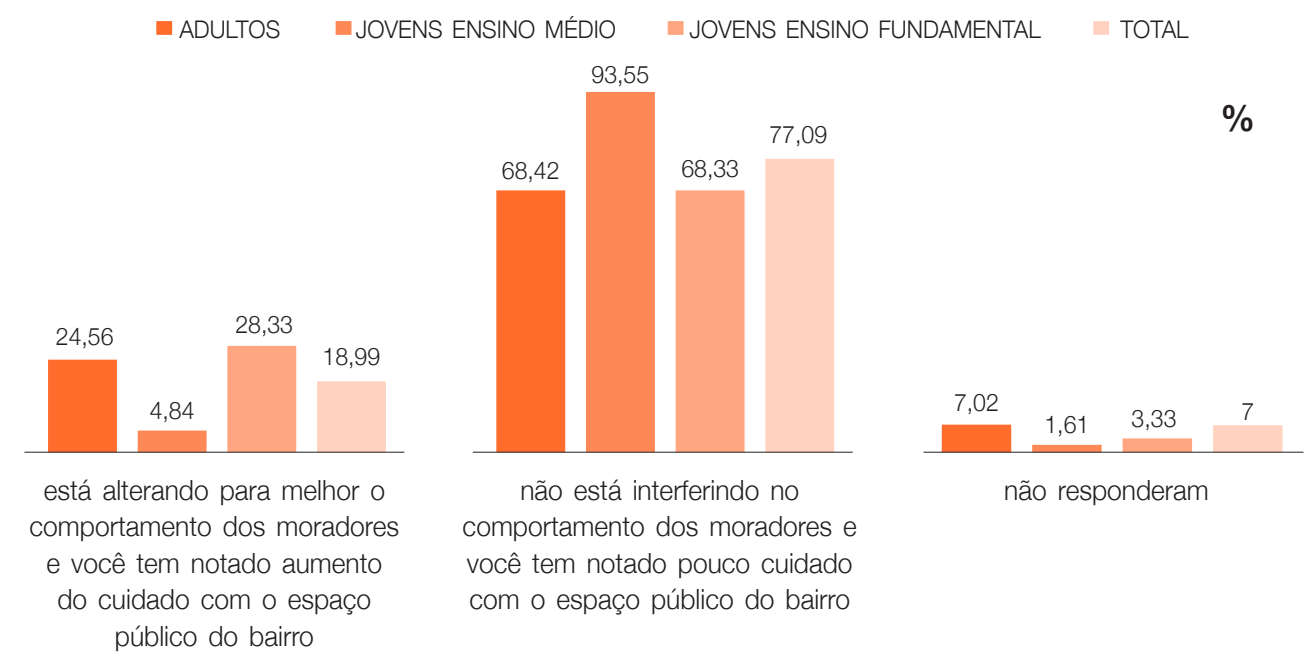

Gráfico 3 - Comunicação ambiental atual: visão do munícipe

Entendemos, em face desse dado e a muitos outros por nós recolhidos durante o trabalho de campo, que a internalização de valores ambientais coadunados à vida urbana carece de preparação mais cuidada do cidadão por parte das múltiplas instâncias comunicativo-educativas às quais cabe planejar/executar 
abordagens viáveis para trazer o morador citadino à observação, à reflexão, ao estudo — formal/informal/não formal — da problemática socioambiental urbana.

Urge, pois, robustecer pontes participativas que questionem os atuais "desvalores" ambientais presentes (objetiva e subjetivamente) no ideário coletivo. Neste caso, convém frisar alguns contributos advindos da intersecção entre a Comunicação e a Educação — os aportes educomunicativos — como forma de ampliar espaços de intervenção capazes de contribuir para a formação de novos agentes sociais, voltados "ao pensar e ao agir no interior de um quadro histórico marcado por novos modos de organizar, distribuir e receber o conhecimento e a informação"9. A perspectiva educomunicativa, transdisciplinar, de acordo com Ismar Soares, coaduna-se com "o tratamento de assuntos complexos no âmbito dos denominados "temas transversais", como o meio ambiente ${ }^{10}$ — este que em nossa visão passa a ser tema central para melhorar a existência nos conglomerados humanos.

O principal desafio hoje é que a urbe crie as condições necessárias para garantir aos cidadãos uma qualidade de vida, no mínimo, aceitável, afirma Pedro Jacobi. Tal repto convoca a proposição de uma nova cidadania ambiental - e esta envolve diretamente a participação do cidadão. O pesquisador afirma, ainda, que embora os mecanismos de envolvimento nas decisões ambientais tenham avançado e se institucionalizado nos últimos tempos, a grande maioria da população não toma parte deles, por desconhecimento de sua existência ou por descrença em sua eficácia ${ }^{11}$.

Cabe ponderar, portanto, que as redes de conexão social da contemporaneidade evidenciam alcance para a promoção de um processo participativo em que a população tenha, de fato, voz e vez — desde que não manipuladas por interesses mercantis travestidos de preocupação ambiental. Heloiza Matos lembra que o processamento da informação feito por diferentes atores e por meio de diversos fluxos comunicativos configura maior conhecimento das regras do jogo político por parte dos cidadãos, que mobilizam informações disponibilizadas pela mídia e pela conversação diária. Tal mobilização de conhecimentos faculta-lhes "elaborar estratégias mais eficazes de participação e de cobrança de maior transparência e accountability (prestação de contas) de instituições governamentais"12.

Frise-se, também, a necessidade de acompanhamento permanente (por todos aqueles que buscam, além do próprio engajamento, o envolvimento coletivo com o meio ambiente) dos processos democráticos que estimulem as pessoas a "fazer com"13. No distrito por nós estudado, há poucos lugares públicos utilizados para promover a deliberação coletiva sobre problemas urbanos por meio da reunião de moradores. Esta característica pouco contributiva coloca tal circunscrição geográfica na contramão do sentido do público "como dimensão de todos", para usar os termos de Pedro Lemos, segundo o qual política e cidade precisam ser "entendidos como comunidade"14.

Se vislumbramos a diluição do sentido de comunidade em certas regiões da malha urbana - entre outros motivos, pela própria configuração do espaço físico —,
9 CITELLI, A. Comunicação e educação - A linguagem em movimento. 3. ed. São Paulo: Senac, 2004, p. 1.

10 SOARES, I. O. Educomunicação: o conceito, 0 profissional, a aplicação: contribuições para a reforma do ensino médio. São Paulo: Paulinas, 2011, p. 73.

11 JACOBI, P. R. Cidade e meio ambiente: percepções e práticas em São Paulo. $3^{a}$. ed. São Paulo: Annablume, 2008 e Idem. Políticas Sociais e ampliação da cidadania. Rio de Janeiro: Editora da Fundação FGV, 2000.

12 MATOS, H. Capital social e comunicação: interfaces e articulações. São Paulo: Summus, 2009, p. 107.

13 PUTNAM, R. D. Bowling Alone - The Collapse and Revival of American Community. Nova York: Simon \& Schuster, 2000, p. 117.

14 LEMOS, Pedro Rocha. Políticas Públicas, Meio Ambiente e Gestão Participativa. In: PÁDUA, Elisabete M. M. de; MATALLO JR. Heitor (orgs.). Ciências sociais, complexidade e meio ambiente. Campinas: Papirus, 2008, p. 143. 
haveremos de constituir estratégias comunicacionais que devolvam ao cidadão a capacidade não só de reflexão crítica sobre o meio onde vive, mas também a possibilidade de compartilhamento dessas reflexões. Uma vez configurados os espaços reflexivos, virtuais ou materiais, torna-se mais fluida a passagem à busca comunitária de soluções socioambientais para mazelas localizadas ou mesmo referentes a lugares que vão além da rua ou do bairro no qual moramos.

Há, ainda, outro ponto a ser pensado quando se deseja que tais espaços funcionem: o valor das mediações aí construídas. Os processos mediadores compõem hoje um quadro geral bastante distinto do encontrado anos atrás, quando as mediações institucionais desempenhavam um papel muito mais forte do que se verifica em nosso tempo ${ }^{15}$. Ou, como lembra Orozco Gómez:

se antes as mediações institucionais próprias das diversas instituições sociais, às quais as audiências pertenciam, eram muito importantes na definição e orientação das produções de sentido, como a escola ou o Estado, por exemplo, agora essas instituições típicas da modernidade e do século passado perderam força ${ }^{16}$.

Paralelamente ao movimento detectado, e reforçando o ponto de vista de Orozco, percebemos a capilaridade comunicacional crescente pela via das redes de relacionamentos e diversas outras trilhas digitais. De acordo com Manuel Castells, existe na sociedade em geral "um salto dos movimentos sociais organizados para os movimentos sociais em rede", cuja base são coalizões constituídas em torno de valores e projetos. Tais deslocamentos, na visão do estudioso, figuram entre os mais importantes na atualidade, e dependem crucialmente da capacidade de comunicação e do estímulo à participação dos cidadãos ${ }^{17}$.

15 Acerca do desajuste entre o tempo social acelerado e ritos das instituições tradicionais, ver: Rosa, Hartmut. Social Acceleration. A New Theory of Modernity. Nova York: Columbia University Press, 2013.

16 OROZCO GÓMEZ,

G. Comunicação social

e mudança tecnológica: um cenário de múltiplos desordenamentos. In: MORAES, D. (org.). Sociedade midiatizada. Mauad, 2006, p. 89.

17 CASTELLS, M. Internet e sociedade em rede. In: MORAES, D. (org.). Por uma outra comunicação. Rio de Janeiro: Record, 2003, p. 277.

18 Idem, p. 17, grifo nosso.
A análise da capilaridade comunicacional que cada vez mais se presta aos movimentos de valores - quando observada a partir do prisma que nos interessa investigar - leva-nos, entre outras implicações, à reflexão sobre a produção de sentido ambiental ligado a múltiplas interfaces. Uma delas perpassa o trinômio Comunicação-Educação-Ciência Ambiental. Citelli, analisando liames entre Comunicação/Educação, recorda-nos que a reflexão crítica acerca dos processos comunicacionais hoje não é o que denomina "compreensão amarga da busca permanente dos fatores de alienação, mentira de classe, manipulação etc.", mas se trata de

instaurar uma prática de busca e entendimento dos processos constituidores dos sentidos, algo comprometido com o encontro das estruturas significativas, sejam elas de puro deleite, prazer difuso provocador do riso, sobriedade analítica, seja mesmo a necessária resposta social que pede participação e envolvimentos transformadores ${ }^{18}$.

Nessa perspectiva, fortalecer a interface Educação e Ciência Ambiental como elemento passível de colaboração na mudança das condições socioecológicas que marcam as grandes cidades depende da contribuição decisiva dos transcursos comunicacionais na geração de sentidos capazes de envolver a sociedade. 
Loureiro, Layrargues e Castro correlacionam "ecocidadania” e educação brasileira, sobretudo na região sudeste - aquela em que se encontra a cidade de São Paulo e, por conseguinte, o distrito Vila Medeiros, onde recolhemos os dados da pesquisa que orientaram este artigo. Para os autores, o nível reduzido de consciência socioambiental no sudeste tem relação direta com a falta de exercício da ecocidadania: embora concentre o maior número de profissionais com ensino superior e seja a região com maior índice de escolaridade do país, aí se revelam inúmeros casos de irresponsabilidade e menoscabo ambiental. Evidenciam-se, portanto, "equívocos na escolarização, deficiente repercussão dos resultados do processo ensino-aprendizagem no cotidiano dos indivíduos ou, ainda, sua desvinculação com os problemas da vida fora das escolas"19.

No caso do distrito em tela, verificamos que respondentes em processo de escolarização conseguem identificar problemas ambientais nos logradouros pelos quais circulam, mas não parecem encontrar vínculo dessa temática com as questões abarcadas no interior da escola, ou, ainda, nos espaços educativos existentes fora do ambiente escolar.

A perspectiva reducionista ${ }^{20}$ representada pelo oferecimento de "uma abordagem educacional acrítica" e "uma leitura conservadora sobre o mundo do trabalho, a problemática ambiental e o modo de produção capitalista” direciona o fazer educativo para uma ética comportamentalista-individualista que deixa de avaliar o peso dos diferentes atores sociais - Estado, mercado, sociedade, comunidade, indivíduo —, sustenta Novicki²1.

Tal forma de oferecer educação aos jovens inviabiliza o avanço da formação, reflexão e ação tendo em vista a complexidade ambiental contemporânea em particular quando falamos do ensino básico, lugar que reúne os milhões de jovens cuja forma de ver e pensar o mundo pode ser decisiva no trato da temática socioecológica. E também há responsabilidade dos meios de comunicação nesse processo equivocado, consoante Coimbra, para o qual os media "produzem ou retransmitem mensagens e programas de interesse ambiental, porém, muitas vezes, inadequados ou reducionistas”, razão pela qual seus efeitos se tornam duvidosos junto aos cidadãos ${ }^{22}$.

Uma abordagem educomunicativa bem planejada poderia redirecionar os fluxos de educação ambiental em circulação tanto nos dispositivos midiáticos quanto nas escolas e demais instituições/entidades/instâncias em que essa comunicação ambiental se realiza. O esforço permitiria reverter certa dinâmica maquinal que atravessa as apropriações das ofertas comunicativas recebidas diariamente.

\section{CONCLUSÃO}

Os trânsitos discursivos multidimensionais ${ }^{23}$ de natureza socioambiental expostos neste artigo apontam para lacunas nos fluxos de comunicação ambiental operados do poder público em direção aos cidadãos, dos cidadãos em direção
19 Idem, p. 31.

20 NOVICKI, V. Práxis: problematizando consciência e participação na educação ambiental brasileira. In: LOUREIRO, C. F. B. (org). A questão ambiental no pensamento crítico - Natureza, trabalho e educação. Rio de Janeiro: Quartet, 2007; FOLADORI, G. El concepto de desarrollo sustentable treinta años después. Revista Desenvolvimento e meio Ambiente, n. 1, pp. 41-56, jan./jun. 2000. Editora da UFPR; GRÜN, M. Ética e educação ambiental - A conexão necessária. 14. ed. Campinas: Papirus, 2011.

21 NOVICKI, op. cit., p. 140.

22 COIMBRA, J. A. A. Linguagem e Percepção Ambiental. In: PHILIPPI JR, A.; ROMÉRO, M. A.; BRUNA, G. C. (ed.). Curso de gestão ambiental. Barueri: Manole, 2004, p. 546.

23 CITELLI, A. Comunicação e culturas do consumo: novos desafios para a educação. Palestra/mesa-redonda. II Congresso Internacional em Comunicação e Consumo. São Paulo, ESPM, 15 e 16/10/2012. 
ao poder público, entre os cidadãos e nas trocas que envolvem instituições/ entidades, no distrito objeto deste texto.

Do trajeto reflexivo aflora, por conseguinte, aspecto merecedor de análise amiudada, a ser desenvolvida em outro momento, acerca do papel das unidades comunicativas das quais partem e às quais retornam fluxos como aqueles acompanhados ao longo de nossa investigação. Estariam tais trocas facultando a redução da lacuna (comprovada em nossa pesquisa) no que tange ao empoderamento dos munícipes para questionar representações sociais sedimentadas, cuja ancoragem freia/desestimula ou não permite ações ambientais proativas?

Verificamos no percurso investigativo a necessidade de potencializar a chegada, a interpretação e a transformação da informação ambiental urbana de maneira a construir ou restaurar os elos que possibilitem aos moradores refletir e agir sobre "desvios" redutores da qualidade de vida. Estariam os inúmeros aportes midiáticos socioambientais com os quais os cidadãos têm contato contribuindo para a realização desse propósito?

Extrapolando, então, as questões afeitas à região abrangida por nosso trabalho, a partir da experiência acumulada na área da comunicação sobre o meio ambiente e das pontes teóricas que logramos desenvolver sob o prisma educomunicativo, intentamos promover contributo reflexivo mais abrangente, voltado à internalização de valores capazes de realimentar a proatividade cidadã no plano socioambiental. Desse ponto de vista, consideramos: selecionar aportes midiáticos e analisá-los, preferencialmente em grupos, discuti-los de pontos de vista múltiplos - a fim de promover ampliação da reflexão socioambiental em quaisquer esferas vislumbradas como propícias — oferece-se como alternativa importante.

Enfatizamos, pois, a premência de desenvolver na universidade e nas comunidades urbanas projetos que permitam resgatar, reorganizar, reconectar e redistribuir saberes a respeito de comunicação ambiental — discutindo-os com a sociedade civil nos lócus de pesquisa aos quais estejam vinculados os pesquisadores. A ideia do reenvio e da geração de novos fluxos comunicativos em torno da análise dos problemas detectados e comunicados aos moradores da urbe guarda força exponencial, a nosso ver, para redimensionar a participação e o empoderamento cidadão por meio dos multidispositivos comunicacionais.

\section{REFERÊNCIAS}

CASTELLS, M. Internet e sociedade em rede. In: MORAES, D. (org.). Por uma outra comunicação. Rio de Janeiro: Record, 2003.

CITELLI, A. Comunicação e educação - A linguagem em movimento. São Paulo: Senac, 2004, 3. ed.

Comunicação e culturas do consumo: novos desafios para

a educação. Palestra/mesa-redonda. II Congresso Internacional em Comunicação e Consumo. São Paulo, ESPM, 15 e 16/10/2012. 
Educar para a comunicação. Sesc TV, São Paulo, n. 92, p. 10, nov. 2014. Disponível em: < www.sescsp.org.br/online/artigo/8461_ EDUCAR+PARA+A+COMUNICACAO\#/tagcloud=lista $>$. Acesso em: 10 mar. 2014.

COIMBRA, J. A. A. Linguagem e Percepção Ambiental. In: PHILIPPI JR. A.; ROMÉRO, M. A.; BRUNA, G. C. (ed.). Curso de Gestão Ambiental. Barueri: Manole, 2004.

FALCÃO, S. P. Comunicação e educação ambiental na construção de sentidos urbanos. Dissertação de Mestrado em Interfaces Sociais da Comunicação. Escola de Comunicações e Artes, Universidade de São Paulo, São Paulo, 2013.

FOLADORI, G. El concepto de desarrollo sustentable treinta años después. In: Revista Desenvolvimento e Meio Ambiente, n. 1, pp. 41-56, jan./jun. 2000. Editora da UFPR.

GIACOMINI FILHO, G. Comunicação e Qualidade de Vida. In: DENCKER, A. F. M. e KUNSCH, M. M. K. (orgs.). Comunicação e meio ambiente. São Paulo/São Bernardo do Campo: Intercom/Imes, 1996.

GRÜN, M. Ética e educação ambiental - A conexão necessária. 14. ed. Campinas: Papirus, 2011.

JACOBI, P. R. Cidade e meio ambiente: percepções e práticas em São Paulo. 3. ed. São Paulo: AnnaBlume, 2008.

Políticas sociais e ampliação da cidadania. Rio de Janeiro: Editora da Fundação FGV, 2000.

LATOUCHE, S. Pequeno tratado do decrescimento sereno. São Paulo: Editora WMF Martins Fontes, 2009.

LEMOS, P. R. Políticas Públicas, Meio Ambiente e Gestão Participativa. In: PÁDUA, E. M. M.; MATALLO JR. H. (orgs.). Ciências Sociais, complexidade e meio ambiente. Campinas: Papirus, 2008.

LOUREIRO, C. F. B.; LAYRARGUES P. P., CASTRO, R. S. (orgs.). Sociedade e meio ambiente: a educação ambiental em debate. São Paulo: Cortez, 2008.

MATOS, H. Capital social e comunicação: interfaces e articulações. São Paulo: Summus, 2009.

NOVICKI, V. Práxis: problematizando consciência e participação na educação ambiental brasileira. In: LOUREIRO, C. F. B. (org). A questão ambiental no pensamento crítico - Natureza, trabalho e educação. Rio de Janeiro: Quartet, 2007.

OROZCO GÓMEZ, G. Comunicação social e mudança tecnológica: um cenário de múltiplos desordenamentos. In: MORAES, D. (org.). Sociedade midiatizada. Mauad, 2006. 
comunicação \& educação • Ano XX • número 2 • jul/dez 2015

PUTNAM, R. D. Bowling Alone - The Collapse and Revival of American Community. Nova York: Simon \& Schuster, 2000.

ROSA, H. Social Acceleration. A New Theory of Modernity. Nova York: Columbia University Press, 2013.

SALDIVA, P. (et al.). Meio ambiente e saúde: o desafio das metrópoles. São Paulo: Ex-Libris Comunicação Integrada, 2010.

SOARES, I. O. Educomunicação: o conceito, o profissional, a aplicação: contribuições para a reforma do ensino médio. São Paulo: Paulinas, 2011.

SODRÉ, M. A ciência do comum - Notas para o método comunicacional. Petrópolis: Vozes, 2014. 